\title{
A follow-up study of the use of a patient-held record in mental health
}

\author{
AIMS AND METHOD \\ Patient-held records have been \\ introduced in mental health over the \\ past 2 decades. This follow-up study \\ aimed to evaluate one pilot project \\ 5 years after the records were intro- \\ duced. All patients initially inter- \\ viewed 4 years previously were
}

\author{
approached and asked about their \\ use and opinion of the record.
RESULTS
Of the 19 people interviewed, 12 were
still using the record and had a
positive opinion of its usefulness. Of \\ all community mental health team
}

\begin{abstract}
contacts, $72 \%$ were recorded in the patient-held notes.
\end{abstract}

\section{CLINICAL IMPLICATIONS}

Patient-held records are sustainable in a naturalistic clinical setting over the period of 5 years.
Patient-held medical records, used in other areas of health care, have been introduced in mental health in some areas over the past 15 years (McGreevy, 1995; Laugharne \& Stafford, 1996). There have also been a few small-scale studies in which they have been evaluated within this client group (Essex et al, 1990; Reuler \& Balazs, 1991; Stafford \& Laugharne, 1997; Greasley et al, 2000). However, these studies have all been short term, the record being studied over 2 years or less. Even the larger scale randomised control trial by Warner et al (2000) had a follow-up time of 12 months. In order to investigate record use in the longer term, a follow-up of the study by Stafford \& Laugharne (1997) was undertaken 4 years later. The original research evaluated a client-held record for people with long-term mental health problems that had been developed in a locality of Tower Hamlets in 1995. The record aimed to give people more information about, and involvement in, their care, aid communication between professionals and patients and aid communication between professionals. Forty-five people were interviewed and interviewees had used the record for an average of 6 months. Most patients who used the record found it acceptable and useful.

\section{Method}

The follow-up study consisted of a survey of the record holders who had participated in the first survey 4 years earlier. The patients were interviewed about their possession and use of the record and asked the same questions about their view of the record as in the original study. They were asked if they found the record useful, if the information it contained was useful and if there was other information they thought should be included. They were also asked which aspects of the record they liked, and which they disliked, and if they thought it could be improved in any way. Where the patient-held records were available, the records themselves were examined to see how they were used, and so that the entries in the record could be compared to the entries made in the community mental health team (CMHT) notes.

\section{Results}

At the time of the follow up 16 of the original 45 subjects were no longer known to the trust, and a further six people were excluded because they had stopped using the record before the first evaluation. The remaining 23 subjects had an average age of 50 (range 27-62). They all had long-term mental health problems, 17 (74\%) had a diagnosis of schizophrenia and 5 (22\%) affective psychosis. The remaining patient was not interviewed and no diagnosis could be made. Of the 23 patients, 19 were interviewed. Three people were not interviewed on advice from their keyworker because they were too unwell, and a number of attempts to interview the final person proved unsuccessful.

Twelve of the interviewees (63\%) were still using the record at the time of the second survey. Of the people no longer using it, four people stopped using it when they lost it, one when it was full and two reported they still had theirs but didn't use them. The average length of use was 4 years 5 months (ranging from 2 years to 5 years 3 months).

Sixteen (84\%) of the interviewees reported that they found the record useful and $17(89 \%)$ that the information it contained was useful. Asked if there was anything about the record that they liked, 16 respondents reported at least one and up to seven aspects that they liked. Aspects that were appreciated included record of appointments and its small size (each mentioned by 10 respondents). Four people mentioned telephone numbers, three, the names of professionals and two people said medication. Other aspects people liked included being able to show it to the doctor (2), that it could be used in an emergency (2), keeping track of, or making a note of, things (2) and that it was reassuring (1). Aspects that people didn't like were that it was too big (3) and the pages weren't waterproof (1). Fifteen people said that there were no aspects they did not like.

Ten of the 12 people who were using the record had it with them at the time of the interview. The other two had both mislaid their records in the past month, having used them continuously before that (confirmed by their community nurse). Examination of the records showed that the majority of entries were made by CMHT workers. 
Exceptions were an entry made by a psychiatrist and four by one general practitioner (GP). In addition appoint-

original papers ments with other professionals were also noted by CMHT workers, mainly psychiatric out-patient appointments, but also two appointments with a GP and a Care Programme Approach review. Comparison of the entries with CMHT notes showed that they were used for an average of $72 \%$ of contacts with the team.

\section{Discussion}

Although this study is of a small sample using patientheld records and included no standardised outcome measures, it has, nevertheless, two important attributes. The setting is a naturalistic clinical situation in a deprived urban environment and the follow-up period longer than previous studies. In its findings, the proportion of respondents using the records was lower at $62 \%$ than at the time of the original survey ( $82 \%)$. However, the average length of time it had been used had increased by nearly 4 years. Consistency of use remained fairly stable, as $72 \%$ of contacts with staff were being recorded in the patient-held record compared to $74 \%$ of all team contacts in the original study, a decline of only $2 \%$ in 4 years. The range of people writing in the record was smaller at the time of the present study. The users of the record still had a favourable opinion of its usefulness.

The context of the follow-up study was different from the original evaluation, the latter being undertaken as part of a pilot project. At that time a project worker was in place to ensure that professionals and service users were aware of the record and how it could be used. The second study took place after the project, and its attendant support and attention had ended.

It is interesting to note the differences in findings between this study and that of Warner et al (2000), which found a lower rate of usage by patients. Possible reasons for this may include the non-randomisation and consequent self-selection in the present study. This may also account for the client reports of satisfaction found in the present study. Future research could further investigate characteristics of record users, and record refusers / non-users, to identify those groups who find the record most beneficial. Both studies found a certain reluctance among professionals to utilise the record, although this was more marked in the Warner et al (2000) study. Essex et al (1990) reported a similar finding. This suggests that if such records are to be more widely used, the issues of professional reluctance to utilise them should be addressed in future research.

Although there have been a number of pilot projects on patient-held records, this is the only long-term followup survey. The patient-held record continued to be used in the absence of a designated worker to support it and without any other enthusiastic proponent of the project. This would indicate that patient-held records are sustainable in the longer term in a naturalistic clinical setting. They are popular with record holders themselves, who appreciate a number of aspects of the record, such as having information about appointments and telephone numbers and the names of professionals in the one place.

\section{References}

ESSEX, B., DOIG, R. \& RENSHAW, J. (1990) Pilot study of records of shared care for people with mentalillness. BMJ, $300,1442-1446$.

GREASLEY, P., PICKERSGILL, D., LEACH, C., et al (2000) The development and piloting of a patient held record with adult mental health users. Journal of Psychiatric and Mental Health Nursing, 7. 227-231.

LAUGHARNE, R. \& STAFFORD, A. (1996) Access to records and client-held records for people with mental illness. A literature review. Psychiatric Bulletin, 20,338-341.

McGREEVY, P. (1995) Using clientheld records in community nursing

practice. Mental Health Nursing, 15(2) $26-27$

REULER, J. B. \& BALAZS, J. R. (1991) Portable medical record for the homeless mentally ill. BMJ, 303, 446.

STAFFORD, A. \& LAUGHARNE, R. (1997) Evaluation of a client-held record introduced by a community mental health team. Psychiatric Bulletin, 21 $757-759$

WARNER, J.P., KING, M. BLIZARD, R. et al (2000) Patient-held shared care records for individuals with mental illness. Randomised controlled evaluation. British Journal of Psychiatry, 177, 319-324.

*Anna Stafford Occupational Therapist, East London \& the City Mental Health NHS Trust, CPOT, Homerton Hospital, Homerton Row, London E9 6SR, Richard Laugharne Consultant Psychiatrist, Cornwall Healthcare NHS Trust and University of Exeter, Department of Mental Health, Wonford House Hospital, Kenneth Gannon Senior Lecturer in Behavioural Science, Barts and the London, Queen Mary's School of Medicine and Dentistry, School of Occupational Therapy

\section{A survey of academic provision for old age psychiatry in the UK and Ireland}

\section{AIMS AND METHOD}

This paper reports the findings of a 1999 survey of academic old age psychiatry staffing and teaching in UK and Irish medical schools.
RESULTS

Just over half had staff established at the level of senior lecturer or above. These schools devoted more time to undergraduate teaching, covered more topics and used a wider range of teaching methods.

\section{CLINICAL IMPLICATIONS}

There is a need for further academic development in old age psychiatry to drive the development of the speciality, and to ensure that all medical undergraduates receive an adequate training in this subject area. 